\title{
Dexamethasone inhibits NF-кBp65 and HMGB1 expression in the pancreas of rats with severe acute pancreatitis
}

\author{
SHANGPING ZHAO ${ }^{1}$, JINMING YANG ${ }^{2}$, TING LIU ${ }^{2}$, JUANXIAN ZENG ${ }^{3}$, LIANGLIANG MI ${ }^{2}$ and KAIMIN XIANG $^{2}$ \\ ${ }^{1} \mathrm{ICU}$; Departments of ${ }^{2}$ Gastrointestinal Surgery and ${ }^{3}$ General Surgery, \\ The Third Xiangya Hospital of Central South University, Changsha, Hunan 410013, P.R. China
}

Received January 2, 2018; Accepted August 23, 2018

DOI: $10.3892 / \mathrm{mmr} .2018 .9595$

\begin{abstract}
Severe acute pancreatitis (SAP) starts as a local inflammation of pancreatic tissue that induces the development of multiple extra-pancreatic organ dysfunction; however, the underlying mechanisms remain unclear. The present study was designed to evaluate the effect of dexamethasone (DXM) on pancreatic damage and to investigate the role of high-mobility group box-1 (HMGB1) and nuclear factor- $\kappa \mathrm{B}$ $(\mathrm{NF}-\kappa \mathrm{Bp} 65)$ in the development of SAP in animal and cell models. For the in vivo experiment, 35 Sprague-Dawley rats were randomly assigned to three groups: The sham-operation control group, the SAP group and the DXM treatment group. Histological analysis revealed that, when DXM was infused into SAP rats, edema formation and structural alterations with necrosis were reduced, and the number of apoptotic cells was markedly reduced. In addition, compared with the SAP group, the expression level of HMGB1 was significantly decreased in the nucleus and the expression level of $\mathrm{NF}-\kappa \mathrm{Bp} 65$ was significantly decreased in the cytoplasm from rats treated with DXM. In vitro, DXM was able to suppress the apoptosis and cell death induced by caerulein (CAE), and DXM could suppress the expression of $\mathrm{NF}-\kappa \mathrm{Bp} 65$ and HMGB1 induced by CAE, as demonstrated by western blotting and immunofluorescence analysis. Therefore, these results provide an experimental basis for investigating the underlying therapeutic mechanisms of DXM treatment for SAP.
\end{abstract}

Correspondence to: Dr Kaimin Xiang, Department of Gastrointestinal Surgery, The Third Xiangya Hospital of Central South University, 138 Tongzipo Road, Yuelu, Changsha, Hunan 410013, P.R. China

E-mail: xiangkaiming2017@163.com

Abbreviations: SAP, severe acute pancreatitis; DXM, dexamethasone; HMGB1, high-mobility group box-1; NF- $\kappa$ B, nuclear factor- $\kappa \mathrm{B}$; CAE, caerulein; SIRS, systemic inflammatory response syndrome; TNF, tumor necrosis factor; TCA, sodium taurocholate solution; HE, hematoxylin-eosin; TUNEL, terminal deoxynucleotidyl transferase, dUTP nick-end labeling

Key words: dexamethasone, severe acute pancreatitis, high-mobility group box-1, nuclear factor- $\kappa \mathrm{B}$

\section{Introduction}

Acute pancreatitis is a relatively common disease and severe acute pancreatitis (SAP) is associated with a high mortality rate, ranging from $15-40 \%$ (1). SAP starts as a local inflammation of pancreatic tissue and is characterized by the development of systemic inflammatory response syndrome (SIRS) and multiple organ dysfunction (2,3). Unfortunately, despite several years of experimental and clinical research, the precise pathophysiology of SAP, particularly in the clinical context remains unclear. This has precluded the development of definitive treatment modalities for this potentially life-threatening illness.

Experimental and clinical studies over the past decade have reported the profiles of intrapancreatic and circulating cytokines, chemokines, adhesion molecules, transcription factors including nuclear factor (NF)- $\kappa \mathrm{B}$ and high-mobility group box 1 (HMGB1) $(4,5)$, the nucleotide-binding oligomerization domain receptor, Toll-like receptor (TLR)9 (6) and protective pathways, including the heme oxygenase- 1 pathway and the peroxisome proliferator-activated receptor- $\gamma$ which are involved in SAP (7).

$\mathrm{NF}-\kappa \mathrm{B}$ has increasingly gained attention over the past several years as a factor in human inflammation, immune regulation and cancer biology. Studies from the last two decades have suggested that $\mathrm{NF}-\kappa \mathrm{B}$ is an early, major activator of pro-inflammatory mediators in the pathogenesis of SAP (8-10). The HMGB1 protein, as a late mediator of endotoxin lethality, was demonstrated to exhibit a delayed release by cultured macrophages of more than $8 \mathrm{~h}$ following stimulation with endotoxin, tumor necrosis factor (TNF), or interleukin (IL)-15 (11,12). Furthermore, previous studies have demonstrated that HMGB1 may serve an important role in SAP $(9,11)$ and it may act as a key inflammatory mediator that participates in the development of SIRS and multiple organ damage in SAP (10). HMGB1, TLR4 and NFאB are possible therapeutic targets for SAP treatment; therefore, HMGB1 antagonists, TLR4 antagonists and NFאB inhibitors should be considered. TLR4 antagonists are the closest to being used in a clinical setting for SAP treatment. Two TLR4 antagonists, namely VGX-1027 and eritoran are already in clinical development (13-16).

The inhibition of HMGB1 by sodium butyrate has been reported to have beneficial effects on SAP development; 
however, sodium butyrate is not a specific HMGB1 inhibitor (17).

Dexamethasone (DXM), a type of steroid medication, can improve microcirculation and inhibit enzymes and inflammatory mediators (18). It has been used to treat SAP, but its protective effects and associated mechanisms on pancreatic injury remain unclear. In the present study, it was hypothesized that HMGB1 and NF- $\mathrm{KBp} 65$ are involved in the therapeutic mechanism through which DXM acts on SAP. Experiments were performed to investigate the influence of DXM on the expression levels of NF- $\mathrm{KBp} 65$ and HMGB1, as well as on apoptosis, in pancreatic cells of SAP rats, to observe the therapeutic efficacy and investigate the underlying therapeutic mechanisms of DXM treatment.

\section{Materials and methods}

Materials and reagents. Sodium taurocholate solution (TCA) was obtained from Beijing Solarbio Science \& Technology Co., Ltd., (Beijing, China) and DXM injections were obtained from Hubei Tianyao Pharmaceutical Co., Ltd., (Fancheng, China) chloral hydrate was purchased from Sangon Biotech Co., Ltd., (Shanghai, China). The HMGB1 antibody was from Abcam (Cambridge, UK) and the NF- $\kappa$ B p65 antibody was from Cell Signaling Technology, Inc., (Danvers, MA, USA).

Animals. In total, 35 male Sprague Dawley rats, 6-8 weeks old and weighing between 200-250 g, were purchased from Hunan Slake Jingda Experimental Animal Co. Ltd., (Changsa, China). The study was approved by the Ethics Committee of Central South University (Changsa, China).

Experimental model and groups. Rats were raised in rooms with a 12 -h light/dark cycle at $25^{\circ} \mathrm{C}$ for 1 week prior to the experiment. Rats were fasted for $12 \mathrm{~h}$ and given food and fresh tap water ad libitum up to the experiment. Anesthesia was administered by intraperitoneal injection of $10 \%$ chloralic hydras $(0.3 \mathrm{ml} / 100 \mathrm{~g})$. The SAP model was induced by the standard retrograde infusion of a freshly prepared 5\% TCA into the biliopancreatic duct following laparotomy. The 35 rats were randomly divided into three groups: (i) Sham-operation control group (sham group, $n=5$ ), where rats received an equivalent volume of normal saline following a successful sham operation; (ii) SAP model group (SAP group, $n=15$ ), where rats received an equivalent volume of 5\% TCA; and (iii) DXM treatment group (DXM group, $n=15$ ), where rats were administered one dose of DXM $(0.5 \mathrm{mg} / 100 \mathrm{~g})$ intravenously in the tail following successful SAP induction. The rats were sacrificed by dislocation of the neck in the state of anesthesia at designated time-points following the induction of pancreatitis.

Histological examination. For histological analysis, pancreas tissue specimens were fixed in $4 \%$ formaldehyde at room temperature for 3 days, embedded in paraffin, sectioned at $4 \mu \mathrm{m}$ and treated with hematoxylin-eosin (HE) staining for $10 \mathrm{~min}$ at room temperature. The terminal deoxynucleotidyl transferase (TdT) dUTP nick-end labeling (TUNEL) assay was used to examine the apoptotic cells in the pancreas. Following staining with $0.5 \%$ hematoxylin for $15 \mathrm{~min}$ at room temperature, the nuclei of healthy cells were stained blue, while those in apoptotic cells presented brown/yellow staining. Integrated optical density (IOD) analysis was used to indirect reaction the apoptosis. The expression levels of HMGB1 and NF-кBp65 in the pancreas were examined by immunohistochemistry (IHC). Specimens were mounted in Permount and examined using routine light microscopy.

Cell culture. AR42J pancreatoma cells were obtained from American Type Culture Collection, (Manassas, VA, USA) and cultured in a humidified atmosphere with $5 \% \mathrm{CO}_{2}$ at $37^{\circ} \mathrm{C}$. The cells were treated with $10^{-8} \mathrm{~mol} / \mathrm{L}$ caerulein (CAE) and/or DXM. Experiments were assigned to three groups: CK group, CAE group and DXM group. In the DXM group, cells were co-treated with CAE and $10^{-6}, 10^{-7}$ or $10^{-8} \mathrm{~mol} / \mathrm{L}$ DXM for $24 \mathrm{~h}$. In the CK group, which acted as the control group, the AR42J cells were only treated with PBS. Cells in the CAE group were treated with CAE alone.

Detection of cellular apoptosis assay. For this experiment, $2 \times 10^{6}$ cells were plated into $60-\mathrm{mm}$ dishes and then treated with or without CAE/DXM for $24 \mathrm{~h}$. Cellular apoptosis was detected using the AnnexinV-fluorescein isothiocyanate Apoptosis kit (BD Biosciences, Franklin Lakes, NJ, USA) and a FACSCanto II flow cytometer (BD Biosciences), following the manufacturer's protocol.

Cell survival assay. AR42J cells $\left(5 \times 10^{3}\right.$ cells/well) were seeded into a 96-well plate and a MTT-based assay was performed after $24 \mathrm{~h}$. DMSO $(150 \mu \mathrm{l})$ was used to dissolve the purple formazan and the absorbance at $570 \mathrm{~nm}$ was measured to determine the cell survival rates.

Immunofluorescence assay. Immunofluorescence was performed on AR42J cells following blocking with 1 X PBS/5\% Normal Goat Serum (005-000-121; Jackson ImmunoResearch Laboratories, Inc., West Grove, PA, USA)/0.3\% Triton X-100 at room temperature for $60 \mathrm{~min}$ using anti-HMGB1 (1:500; cat. no. ab79823; Abcam), and anti-NF-кBp65 (1:500; cat. no. 8242; Cell Signaling Technology, Inc.) primary antibodies and cy3-conjugated secondary antibodies (1:500; Abcam). Nuclei were counterstained with DAPI (1:1,000; Sigma Aldrich; Merck KGaA, Darmstadt, Germany) for $1 \mathrm{~h}$ at room temperature and cover slips were mounted with Fluorescence Mounting Medium (Dako; Agilent Technologies, Inc., Santa Clara, CA, USA) and examined using a fluorescence microscope.

Western blotting. AR42J cells were harvested using RIPA buffer (P002A; Auragene; Hunan Aijia Biotechnology Co., Ltd., Hunan, China) and a BCA Protein Quantitation kit used for protein determination. Proteins were subjected to SDS-PAGE and immunoblotting, as previously described (19). A total of $30 \mu \mathrm{g}$ protein per lane was separated by $10 \%$ SDS-PAGE, transferred onto polyvinylidene fluoride membranes (EMD Millipore, Billerica, MA, USA), blocked with 5\% skimmed milk for $1 \mathrm{~h}$ at room temperature and incubated with primary antibodies at $4^{\circ} \mathrm{C}$ overnight: Anti-HMGB1 (1:1,0000; cat. no. ab79823; Abcam), anti-NF-кBp65 (1:1,1000; cat. no. 8242; Cell Signaling Technology, Inc.) and anti- $\beta$-actin $(1: 1,1000$; cat. no. 3700; Cell Signaling Technology, Inc.). Then the blots were incubated with the corresponding secondary antibodies 
(1:5,000; sheep anti-rat; SA001 and sheep anti rabbit; SA009 Auragene; Hunan Aijia Biotechnology Co., Ltd.) at room temperature for $2 \mathrm{~h}$. An AuraECL Chemiluminescence detection kit (Auragene; Hunan Aijia Biotechnology Co., Ltd.) was used for visualization.

Statistical analysis. All results are expressed as the mean \pm standard deviation from 3 independent experiments. One-way analysis of variance was used for statistical analysis and Tukey post hoc test was used for verification. $\mathrm{P}<0.05$ was considered to indicate a statistically significant difference and SPSS version 17 (SPSS, Inc., Chicago, IL, USA) was used for analysis.

\section{Results}

Histological alterations in the pancreas. Histological alterations in pancreatic tissues were observed under a light microscope by HE staining, as presented in Fig. 1A. In the sham group, pancreatic interstitial cells demonstrated slight hemorrhage and mild edema. Pancreatic tissue in the SAP group demonstrated increased levels of hemorrhage, edema and structural distortion with necrosis compared with the sham group (data not shown). Notably, when DXM was infused into the SAP rats, edema formation and structural alterations with necrosis were reduced. In addition, the therapeutic influence of DXM was time-dependent and differences between the DXM group, and the SAP group were especially noticeable after $12 \mathrm{~h}$. (data not shown). The number of apoptotic acinar cells increased in the SAP group compared with the sham group. Similarly, following DXM infusion, the number of apoptotic cells was markedly reduced compared with the SAP group and this reduction was time-dependent, with a significant reduction observed after $6 \mathrm{~h}(\mathrm{P}<0.05$; Fig. $1 \mathrm{~B}$ and $\mathrm{C})$.

IHC analysis of $N F-\kappa B p 65$ and $H M G B 1$ expression in the pancreas. Inflammatory mediators serve key roles in the pathogenesis of SAP. In the present study, alterations in NF- $\kappa \mathrm{Bp} 65$ and HMGB1 expression were examined in the pancreas. In the sham group, the detection of HMGB1 was very weak in the nucleus (Fig. 2A) and a low level of NF- $\kappa$ Bp65 was concentrated in the cytoplasm (Fig. 2B). In the SAP group, intense immunoreactivity with HMGB1 and NF- $\mathrm{NBp} 65$ was detected in the nucleus and cytoplasm (Fig. 2). In the DXM group, the expression levels of HMGB1 and NF- $\mathrm{HBp} 65$ were decreased in the nucleus and the cytoplasm, respectively (Fig. 2), compared with the SAP group.

DXM regulates cell apoptosis in AR42J cells treated with CAE. To confirm that DXM is involved in the regulation of cellular apoptosis of AR42J cells treated with CAE, flow cytometry was performed. As presented in Fig. 3, compared with the control group, apoptosis was significantly increased in AR42J cells following treatment with $\mathrm{CAE}(\mathrm{P}<0.001$; Fig. $3 \mathrm{~A}$ and $\mathrm{B})$. DXM could significantly suppress apoptosis induced by CAE $(\mathrm{P}<0.01)$ and the reduction in apoptosis was associated with the DXM concentration (Fig. 3B).

Cell survival assay in AR42J cells treated with CAE and DXM. Compared with the CK group, cell survival was significantly inhibited in the CAE group $(\mathrm{P}<0.001)$ and could be significantly improved by DXM treatment $(\mathrm{P}<0.05)$. Additionally, a positive association was demonstrated between cell viability and DXM concentration (Fig. 3C).

Effect of DXM on HMGB1 and NF- $\mathrm{HBp} 65$ expression in AR42J cells. Immunofluorescence (Fig. 4A) and western blotting (Fig. 4B) analyses demonstrated that HMGB1 and $\mathrm{NF}-\kappa \mathrm{Bp} 65$ were expressed at low levels in AR42J cells treated with PBS (CK group), were expressed at a high level in the CAE group, and were expressed at an intermediate level in the DXM and CAE co-treated group. The expression of HMGB1 and NF- $\mathrm{KBp} 65$ decreased in a dose-dependent manner with DXM treatment and reached the lowest levels when treated with $10^{-6} \mathrm{M} \mathrm{DXM}$, compared with the CAE group (Fig. 4).

\section{Discussion}

SAP is an acute, critical illness with rapid onset, long duration and rapid progress that results in massive necrosis of pancreatic tissue, extrapancreatic multiple organ failure, and a high mortality rate. Despite advances in treatment techniques, the mortality of SAP has improved slowly over the past several decades and the pathogenesis of SAP has not been completely clarified $(20,21)$. However, experts have focused on inflammatory mediators and their corresponding antagonists as potential therapeutic targets, due to their contribution to the injury of the pancreas and other organs, frequently resulting in patients succumbing to the condition.

DXM is a long-acting corticosteroid. Its therapeutic effects on SAP are primarily associated with suppressing the production and/or actions of inflammatory mediators, enhancing the anti-stress capacity of the body, reducing endotoxemia, and scavenging oxygen free radicals $(22,23)$. In the present study, to investigate the protective effects of DXM on the pancreas of SAP rats the effect of DXM treatment on the expression levels of NF- $\kappa$ Bp65 and HMGB1, as well as on the histopathology of the pancreas in rats with SAP, was investigated.

$\mathrm{NF}-\kappa \mathrm{Bp} 65$ is a transcription factor that regulates various genes involved in inflammatory and immune responses, including cytokine and adhesion molecules (24). TNF- $\alpha$ expression is directly regulated by $\mathrm{NF}-\kappa \mathrm{Bp} 65$, as there are $\mathrm{NF}-\kappa \mathrm{Bp} 65$ binding sites on the TNF- $\alpha$ promoter. Research has demonstrated that the inhibition of NF- $\mathrm{NBp} 65$ can result in decreased expression levels of cytokines, including TNF- $\alpha$, reducing the inflammatory response in organisms. The role of $\mathrm{NF}-\kappa \mathrm{Bp} 65$ activation in the pathogenesis of SAP was previously reviewed (25) and in a later investigation, this laboratory demonstrated evidence that the upregulation of NF- $\mathrm{Bp} 65$ could aggravate SAP-induced pancreatic injury (26). $\mathrm{NF}-\kappa \mathrm{Bp} 65$ inhibitors in in vitro and in vivo models of SAP have already been studied (27,28). In the present study, DXM

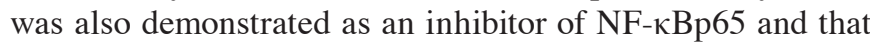
DXM can downregulate the expression of NF- $\kappa \mathrm{Bp} 65$ protein in the pancreatic tissue of SAP rats and in AR42J cells treated with CAE. Previous studies have demonstrated that HMGB1 acts through multiple mechanisms, including through the $\mathrm{NF}-\kappa \mathrm{Bp} 65$ pathway (29). However, it is not certain whether there are binding sites for $\mathrm{NF}-\kappa \mathrm{Bp} 65$ on the HMGB1 promoter. 
A
$3 \mathrm{~h}$

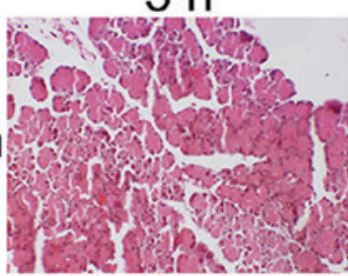

Sham
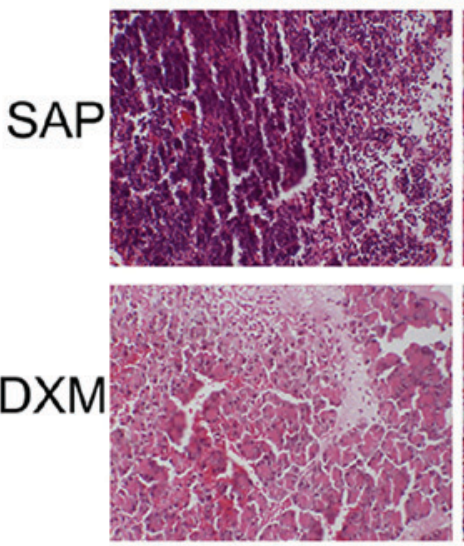

B

Sham
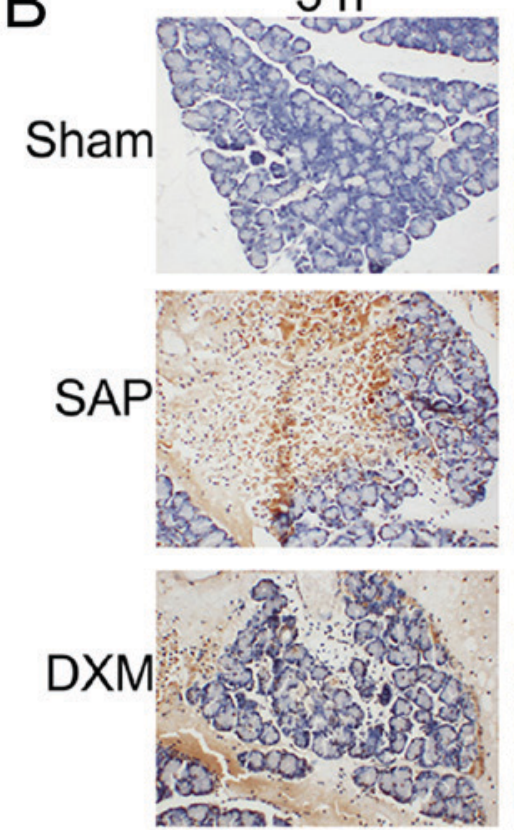

$6 \mathrm{~h}$
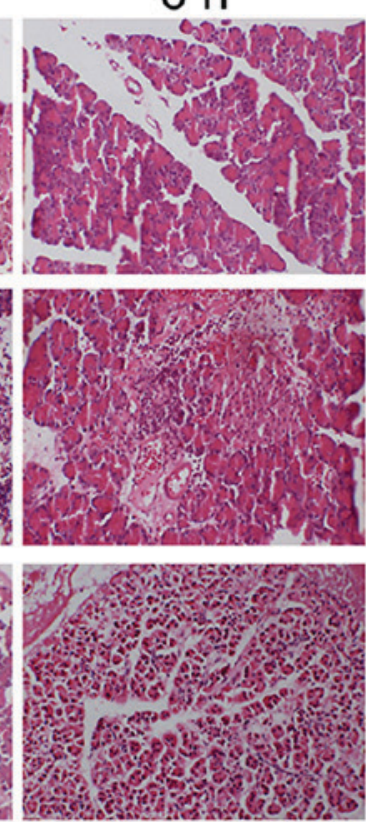

$6 \mathrm{~h}$
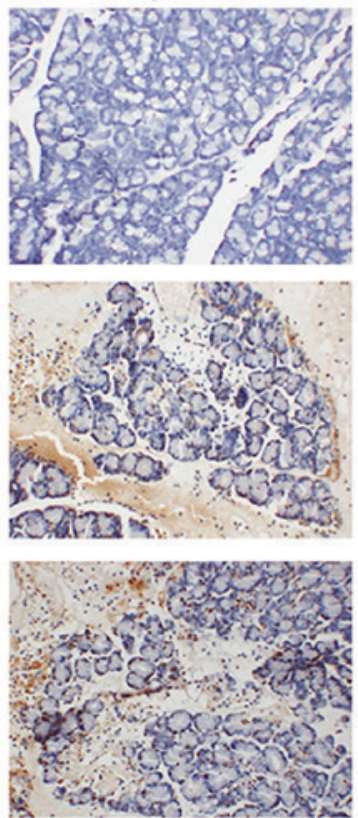

$12 \mathrm{~h}$
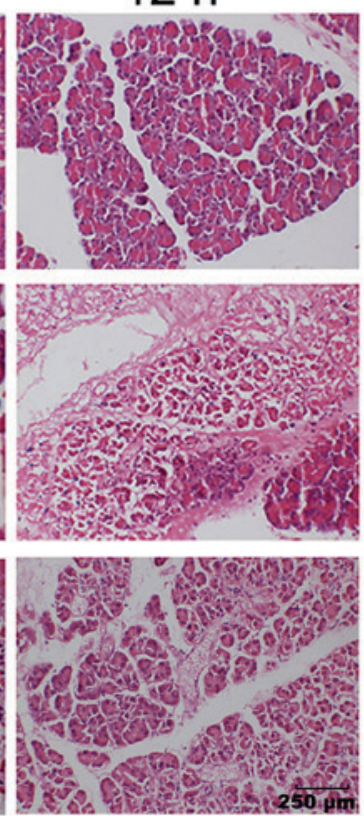

$12 \mathrm{~h}$
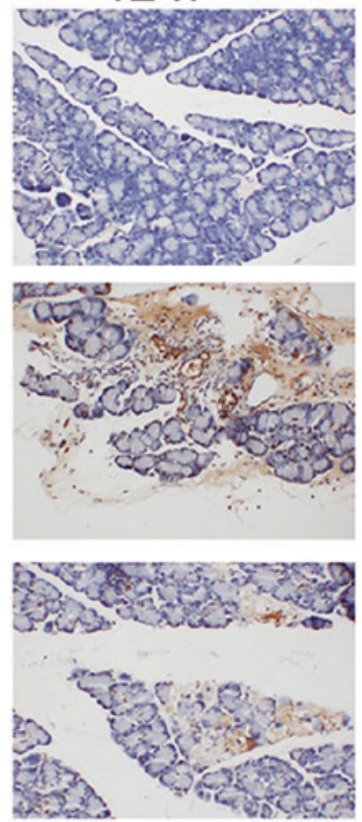

C

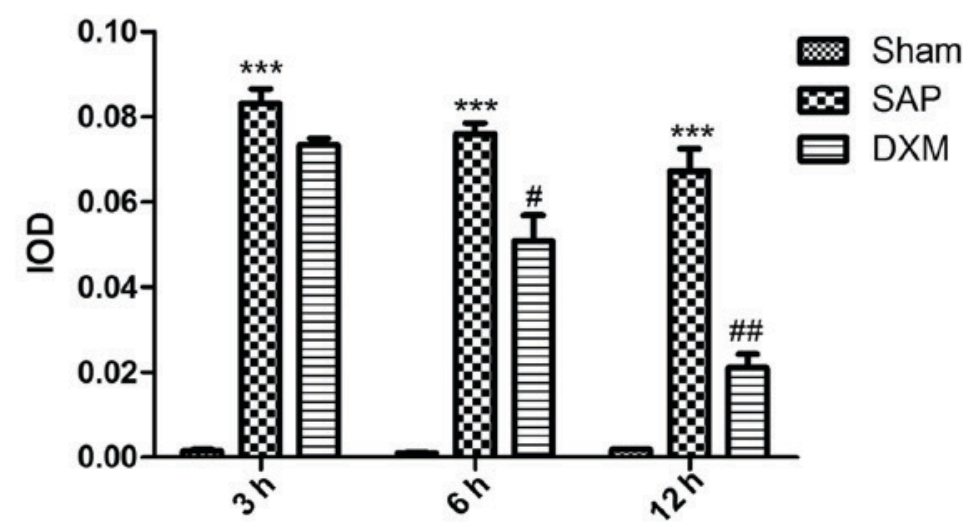

Figure 1. Pathological changes in the pancreas. Pancreases from the sham, SAP and DXM groups were harvested 3,6 or $12 \mathrm{~h}$ following operations and were stained. (A) Mass hemorrhages, edema and structural alterations with necrosis were observed in the pancreas by hematoxylin and eosin staining (magnification, $\mathrm{x} 400$ ). Scale bar represents $250 \mu \mathrm{m}$. (B) The apoptotic acinar cells in the pancreas were observed by TUNEL staining. (C) IOD analysis of TUNEL. Data are presented as the mean \pm standard error of the mean $(n=3)$. ${ }^{\# \#} \mathrm{P}<0.01,{ }^{\#} \mathrm{P}<0.05$ vs. SAP group; ${ }^{* * *} \mathrm{P}<0.001$ vs. Sham group. SAP, severe acute pancreatitis; DXM, dexamethasone-treated; TUNEL, terminal deoxynucleotidyl transferase dUTP nick-end labeling; IOD, integrated optical density. 
A
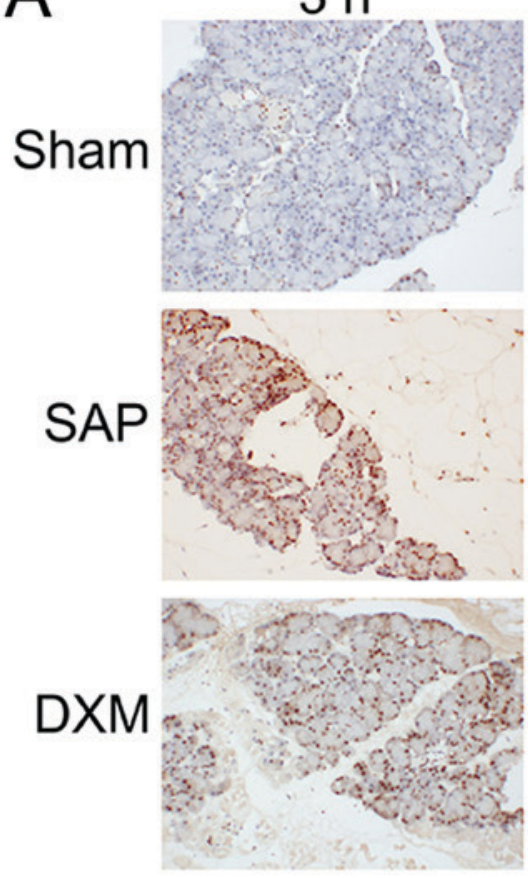

B
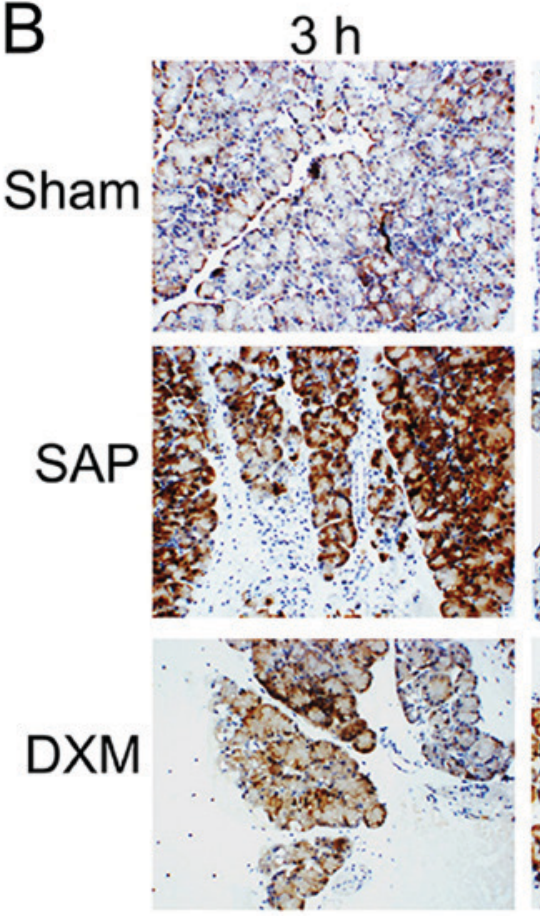

$6 \mathrm{~h}$
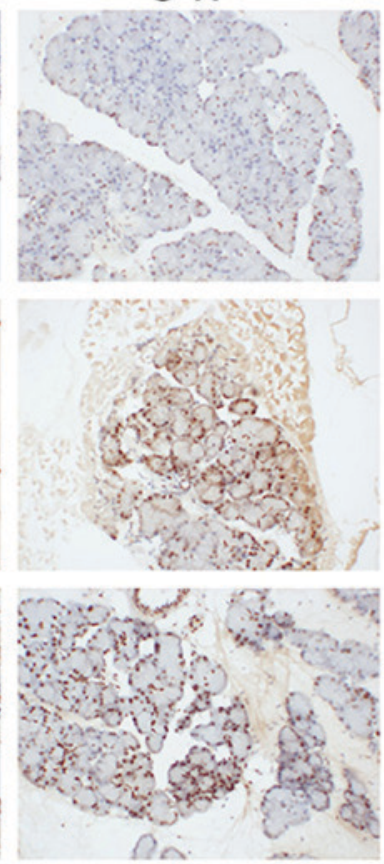

$6 \mathrm{~h}$
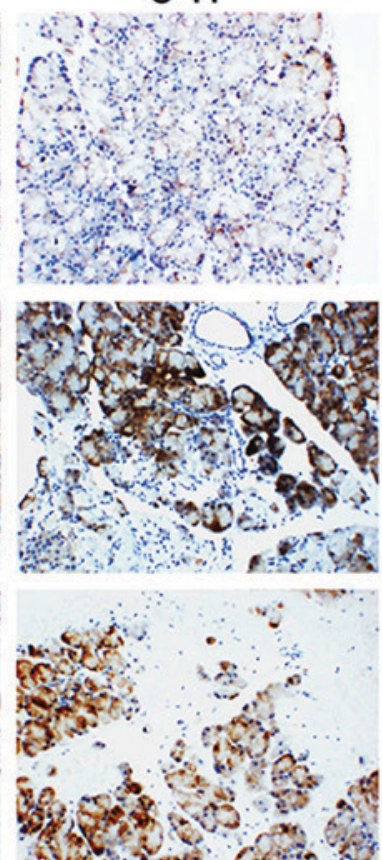

$12 \mathrm{~h}$
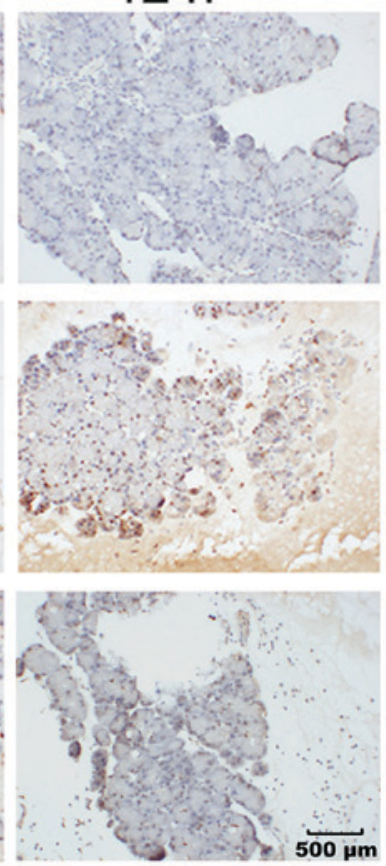

$12 \mathrm{~h}$
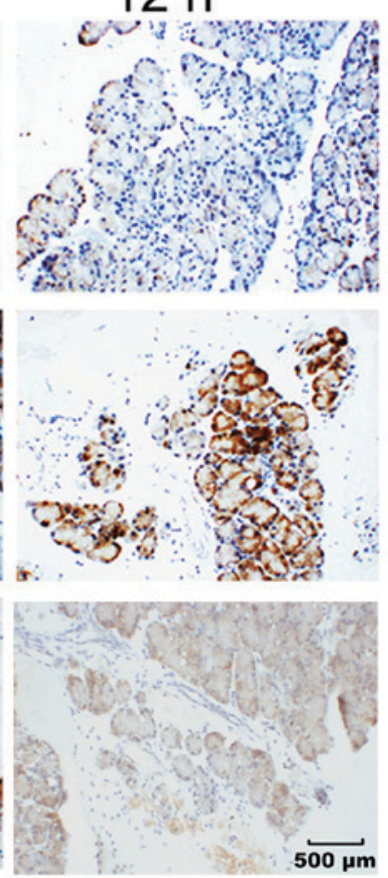

Figure 2. Immunohistochemical analysis. To detect the effects of DXM on HMGB1 and NF- $\mathrm{KB}$ protein expression levels in pancreatic tissue from sodium taurocholate solution-treated rats, HMGB1 and NF- $\mathrm{kBp} 65$ proteins were detected in pancreatic tissue from animals sacrificed 3, 6, or 12 h following operation in the sham, SAP and DXM groups. (A) The expression of HMGB1. (B) The expression of NF- $\mathrm{kBp} 65$ (magnification, x200). Scale bar represents 500 $\mu \mathrm{m}$.

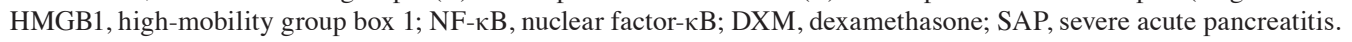

Therefore, it remains unclear whether HMGB1 expression is directly regulated by NF- $\mathrm{kBp} 65$.

HMGB1, a DNA-binding intranuclear protein, is a late activator of the inflammatory cascade when released into the extracellular space. HMGB1 is released from necrotic cells or secreted by activated monocytes or macrophages. HMGB1 induces pro-inflammatory cytokines in human monocytes via TLR4 and NF- $\kappa B$ activation (30). HMGB1 can mediate cell-to-cell signaling by binding to the receptor for advanced glycation end products and toll-like receptors (TLR), especially TLR-2 and TLR-4, to enhance the inflammatory response $(29,31)$. As a late-phase mediator, HMGB1 was previously discovered to be upregulated in a number of acute and chronic inflammatory conditions, including sepsis, acute lung injury and rheumatoid arthritis (32-34). In contrast to other known pro-inflammatory cytokines, the delayed kinetics of HMGB1 provide a wide 
A
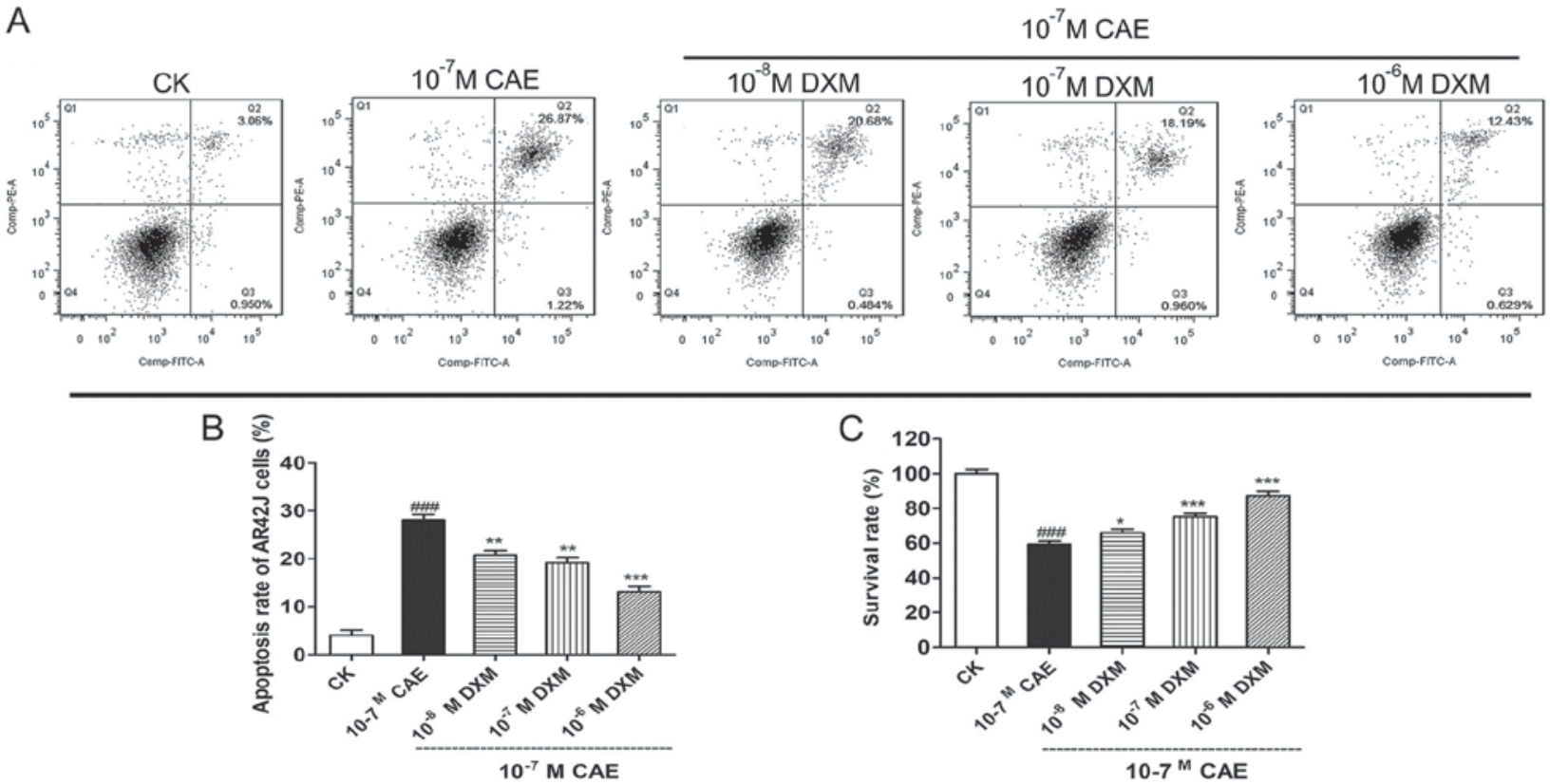

Figure 3. Analysis of AR42J cell survival. (A) Flow cytometry plots and (B) statistical analysis of the rate of apoptosis for cell treated with CAE and DXM. The number of apoptotic AR42J cells treated with CAE is markedly increased compared to the CK and DXM groups, and the number of apoptotic AR42J cells decreased with an increase in DXM concentration. (C) DXM dose-dependently promotes AR42J cell viability, as assessed by the MTT assay. ${ }^{\# \# ~}<0.001$, CK group vs. the CAE group. ${ }^{* * *} \mathrm{P}<0.001,{ }^{* *} \mathrm{P}<0.01$ and ${ }^{*} \mathrm{P}<0.05, \mathrm{CAE}$ group vs. DXM group. Data are the mean \pm standard error ( $=3$ ). CAE, caerulein; DXM, dexamethasone; FITC, fluroescein isothiocyanate.

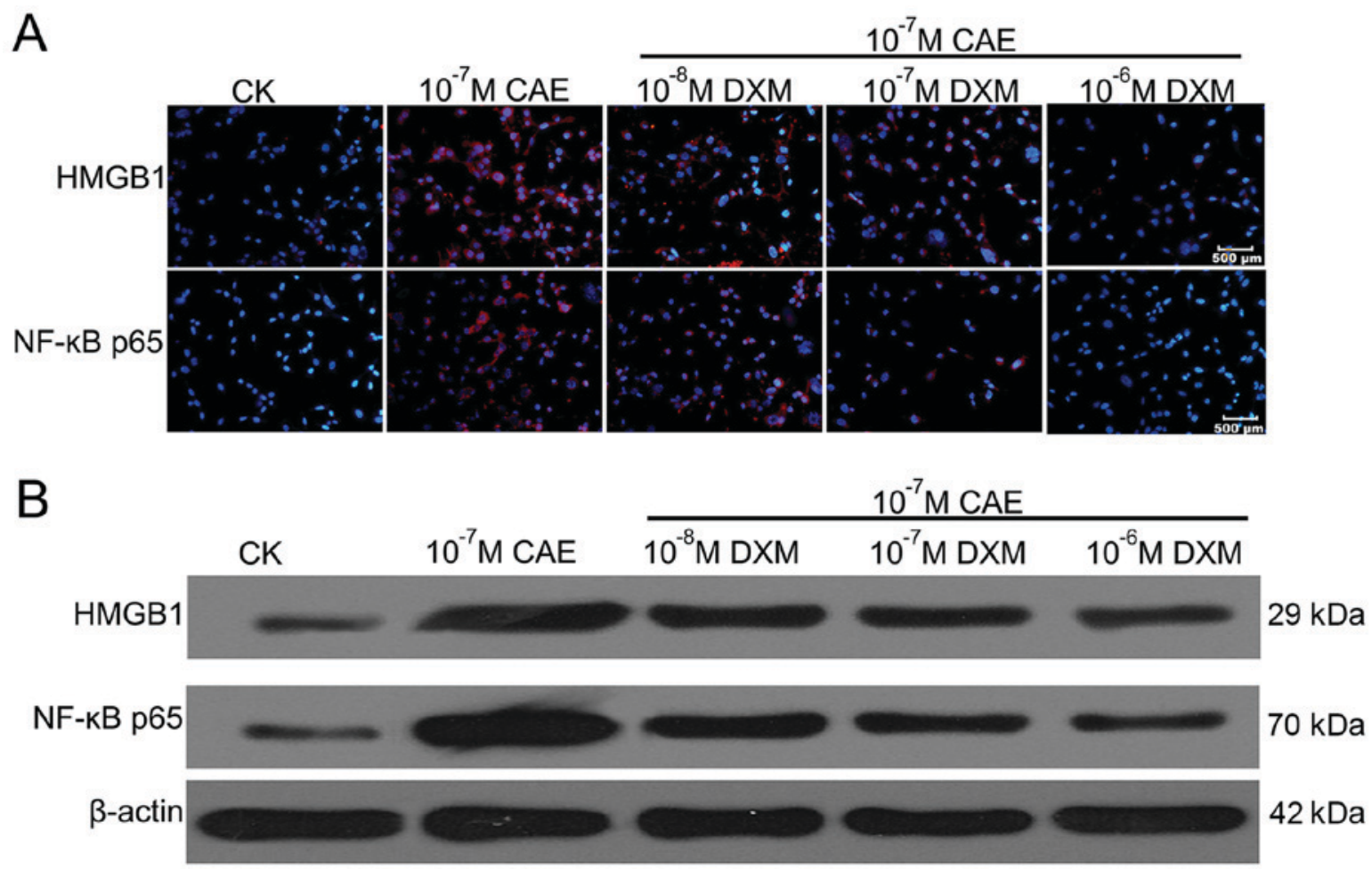

Figure 4. Expression of HMGB1 and NF- $\kappa$ Bp65 in AR42J cells. To examine the effects of DXM on HMGB and NF- $\kappa$ B protein expression in AR42J cells

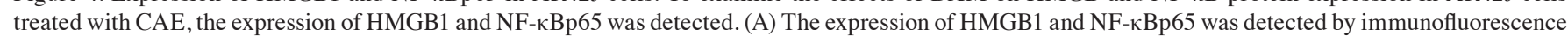
using cy3-conjugated antibodies (red) and DAPI (blue) (magnification, x200). Scale bar represents $500 \mu \mathrm{m}$. (B) Levels of HMGB1, NF- $\mathrm{BBp} 65$ and $\beta$-actin in

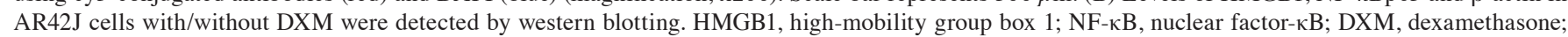
CAE, caerulein.

window of opportunity for therapeutic approaches (35). The present results also highlight the possible beneficial role of anti-inflammatory cytokines, including IL-10 and IL-13, in the pathogenesis of SAP. These cytokines may counteract the type-1 pro-inflammatory cytokines secreted in response to the activation of the TLR4-NF-kB pathway induced by HMGB1. 
As a result, HMGB1 offers the hope of developing an anti-inflammatory therapy that is practical and effective. In a previous study serum HMGB1 levels, were demonstrated to be significantly elevated in patients with SAP and were correlated with disease severity (36). Therefore, it has been speculated that HMGB1 may be a target for anti-inflammatory treatment in SAP. In the present study, it was demonstrated that HMGB1 expression levels increased in the pancreas with SAP and decreased following treatment with DXM, suggesting that HMGB1 may be pivotal for the inflammatory response and organ injury observed in SAP and may be a therapeutic target for SAP. It was hypothesized that elevated HMGB1 levels may represent an aggravating factor in SAP and the associated multiple organ damage. However, HMGB1 affects a number of angiogenesis-associated conditions, including cancer, proliferative diabetic retinopathy and wound healing through the p53 pathway, and it is a promising therapeutic target in a number of tumors, including epidermal tumors, prostate cancer and colon cancer (37-39). Therefore, the exact function of HMGB1 and its mechanism still need to be elucidated. Notably, while investigating the relevance of HMGB1-TLR4-NF- $\mathrm{BB}$-induced pro-inflammatory cytokines in SAP, it was demonstrated that the antibiotic and immunomodulatory agent fusidic acid may prevent pancreatitis through the reduction of TNF- $\alpha$ and IL-8. This is of interest because sodium fusidate is clinically available and could be immediately considered for the treatment of SAP $(40,41)$.

In conclusion, DXM can reduce the levels of NF- $\kappa \mathrm{Bp} 65$ and HMGB1 and mitigate the pathological alterations in the pancreas of rats with SAP and in AR42J cells treated with CAE. In in vivo and vitro experiments, DXM was identified to have a therapeutic effect on SAP. Therefore, NF- $\kappa$ Bp65 and HMGB1 may serve auxiliary roles in the treatment of SAP. Overall, each of these inflammatory mediators has benefits and should be used appropriately in future clinical practice.

\section{Acknowledgements}

Not applicable.

\section{Funding}

The present study was supported by Key project of Hunan science and technology plan (grant no: 2013FJ4093).

\section{Availability of data and materials}

The datasets used during the present study are available from the corresponding author upon reasonable request.

\section{Authors' contributions}

SZ, LM and KX conceived and designed the study. SZ, TL, JZ and JY performed the experiments. SZ and JY wrote the manuscript. KX reviewed and edited the manuscript. All authors read and approved the manuscript and agree to be accountable for all aspects of the research in ensuring that the accuracy or integrity of any part of the work were appropriately investigated and resolved.

\section{Ethics approval and consent to participate}

The present study was approved by the Ethics Committee of Central South University (Changsa, China).

\section{Patient consent for publication}

Not applicable.

\section{Competing interests}

The authors declare they have no competing interests.

\section{References}

1. Uneno Y, Taneishi K, Kanai M, Okamoto K, Yamamoto Y, Yoshioka A, Hiramoto S, Nozaki A, Nishikawa Y, Yamaguchi D, et al: Development and validation of a set of six adaptable prognosis prediction (SAP) models based on time-series real-world big data analysis for patients with cancer receiving chemotherapy: A multicenter case crossover study. PloS One 12: e0183291, 2017.

2. Shen Q, Li Z, Huang S, Li L, Gan H and Du XG: Intestinal mucosal barrier dysfunction in SAP patients with MODS ameliorated by continuous blood purification. Int J Artif Organs 14: 0, 2017.

3. Lipinski M and Rydzewska G: Immature granulocytes predict severe acute pancreatitis independently of systemic inflammatory response syndrome. Prz Gastroenterol 12: 140-144, 2017.

4. Zhang ZW, Zhang QY, Zhou MT, Liu NX, Chen TK, Zhu YF and Wu L: Antioxidant inhibits HMGB1 expression and reduces pancreas injury in rats with severe acute pancreatitis. Dig Dis Sci 55: 2529-2536, 2010

5. Wang B, Xu XB, Jin XX, Wu XW, Li ML, Guo MX and Zhang XH: Effects of $\omega-3$ fatty acids on Toll-like receptor 4 and nuclear factor $\kappa \mathrm{B}$ p56 in the pancreas of rats with severe acute pancreatitis. Pancreas 46: 1267-1274, 2017.

6. Yan Y, Lu B, Li P and Wang J: NOD receptor and TLR9 modulation in severe acute pancreatitisinduced intestinal injury. Mol Med Rep 16: 8471-8476, 2017.

7. Xiong J, Wang K, Yuan C, Xing R, Ni J, Hu G, Chen F and Wang X: Luteolin protects mice from severe acute pancreatitis by exerting $\mathrm{HO}-1$-mediated anti-inflammatory and antioxidant effects. Int J Mol Med 39: 113-125, 2017.

8. Feng C, Li B, Wang LL, Chen LI, Zhou X, Lv FQ and Li TS: Effect of peritoneal lavage with ulinastatin on the expression of NF- $\kappa B$ and TNF- $\alpha$ in multiple organs of rats with severe acute pancreatitis. Exp Ther Med 10: 2029-2034, 2015.

9. LiG,Wu X, Yang L,He Y,Liu Y,Jin X and Yuan H:TLR4-mediated NF- $\mathrm{kB}$ signaling pathway mediates HMGB1-induced pancreatic injury in mice with severe acute pancreatitis. Int J Mol Med 37: 99-107, 2016.

10. Lin YJ, Ding Y, Wu J and Ning BT: Pterostilbene as treatment for severe acute pancreatitis. Genet Mol Res 15, 2016.

11. Yang R, Tenhunen J and Tonnessen TI: HMGB1 and histones play a significant role in inducing systemic inflammation and multiple organ dysfunctions in severe acute pancreatitis. Int J Inflam 2017: 1817564, 2017.

12. Kwak MS, Lim M, Lee YJ, Lee HS, Kim YH, Youn JH, Choi JE and Shin JS: HMGB1 binds to lipoteichoic acid and enhances TNF- $\alpha$ and IL- 6 production through HMGB1-mediated transfer of lipoteichoic acid to CD14 and TLR2. J Innate Immun 7: 405-416, 2015.

13. Stojanovic I, Cuzzocrea S, Mangano K, Mazzon E, Miljkovic D, Wang M, Donia M, Al Abed Y, Kim J, Nicoletti F, et al: In vitro, ex vivo and in vivo immunopharmacological activities of the isoxazoline compound VGX-1027: Modulation of cytokine synthesis and prevention of both organ-specific and systemic autoimmune diseases in murine models. Clin Immunol 123: 311-323, 2007.

14. Fagone P, Muthumani K, Mangano K, Magro G, Meroni PL, Kim JJ, Sardesai NY, Weiner DB and Nicoletti F: VGX-1027 modulates genes involved in lipopolysaccharide-induced Toll-like receptor 4 activation and in a murine model of systemic lupus erythematosus. Immunology 142: 594-602, 2014. 
15. Lee JC, Menacherry S, Diehl MC, Giffear MD, White CJ, Juba R, Bagarazzi ML, Muthumani K, Boyer J, Agarwal V, et al: Safety, bioavailability, and pharmacokinetics of VGX-1027-A novel oral anti-inflammatory drug in healthy human subjects. Clin Pharmacol Drug Dev 5: 91-101, 2016.

16. Lucas K and Maes M: Role of the Toll Like receptor (TLR) radical cycle in chronic inflammation: Possible treatments targeting the TLR4 pathway. Mol Neurobiol 48: 190-204, 2013.

17. Zhang T, Xia M, Zhan Q, Zhou Q, Lu G and An F: Sodium butyrate reduces organ injuries in mice with severe acute pancreatitis through inhibiting HMGB1 expression. Dig Dis Sci 60: 1991-1999, 2015

18. Sellner S, Kocabey S, Zhang T, Nekolla K, Hutten S, Krombach F, Liedl T and Rehberg M: Dexamethasone-conjugated DNA nanotubes as anti-inflammatory agents in vivo. Biomaterials 134 78-90, 2017.

19. Cen C, Li J, Liu J, Yang M, Zhang T, Zuo Y, Lin C and Li X: Long noncoding RNA LINC01510 promotes the growth of colorectal cancer cells by modulating MET expression. Cancer Cell Int 18 45, 2018.

20. Mofidi R, Madhavan KK, Garden OJ and Parks RW: An audit of the management of patients with acute pancreatitis against national standards of practice. Br J Surg 94: 844-848, 2007.

21. Buter A, Imrie CW, Carter CR, Evans S and McKay CJ: Dynamic nature of early organ dysfunction determines outcome in acute pancreatitis. Br J Surg 89: 298-302, 2002.

22. Yubero S, Ramudo L, Manso MA and De Dios I: Mechanisms of dexamethasone-mediated chemokine down-regulation in mild and severe acute pancreatitis. Biochim Biophys Acta 1792: 1205-1211, 2009

23. Jingmin O, Xiping Z, Chun W, Ping Y and Qian Y: Study of dexamethasone, baicalin and octreotide on brain injury of rats with severe acute pancreatitis. Inflamm Res 61: 265-275, 2012.

24. Zhang XP, Zhang L, Chen LJ, Cheng QH, Wang JM, Cai W, Shen HP and Cai J: Influence of dexamethasone on inflammatory mediators and NF-kappaB expression in multiple organs of rats with severe acute pancreatitis. World J Gastroenterol 13: 548-556, 2007.

25. Zhang XP, Zhang L, Xu HM, Xu YP, Cheng QH, Wang JM and Shen HP: Application of tissue microarrays to study the influence of dexamethasone on NF-kappaB expression of pancreas in rat with severe acute pancreatitis. Dig Dis Sci 53: 571-580, 2008

26. Ou JM, Zhang XP, Wu CJ, Wu DJ and Yan P: Effects of dexamethasone and Salvia miltiorrhiza on multiple organs in rats with severe acute pancreatitis. J Zhejiang Univ Sci B 13: 919-931, 2012.

27. Chen Y, Zhao Q, Chen Q, Zhang Y, Shao B, Jin Y and Wu J: Melatonin attenuated inflammatory reaction by inhibiting the activation of $\mathrm{p} 38$ and NFKB in taurocholateinduced acute pancreatitis. Mol Med Rep 17: 5934-5939, 2018

28. Qian D, Wei G, Xu C, He Z, Hua J, Li J, Hu Q, Lin S, Gong J, Meng $\mathrm{H}$, et al: Bone marrow-derived mesenchymal stem cells (BMSCs) repair acute necrotized pancreatitis by secreting microRNA-9 to target the NF- $\mathrm{kB} 1 / \mathrm{p} 50$ gene in rats. Sci Rep 7: $581,2017$.
29. Bi Y, Zhu Y, Zhang M, Zhang K, Hua X, Fang Z, Zhou J, Dai W, Cui Y, Li J and You T: Effect of shikonin on spinal cord injury in rats via regulation of HMGB1/TLR4/NF- $\kappa \mathrm{B}$ signaling pathway. Cell Physiol Biochem 43: 481-491, 2017.

30. Andersson U, Wang H, Palmblad K, Aveberger AC, Bloom O, Erlandsson-Harris H, Janson A, Kokkola R, Zhang M, Yang H and Tracey KJ: High mobility group 1 protein (HMG-1) stimulates proinflammatory cytokine synthesis in human monocytes. J Exp Med 192: 565-570, 2000

31. Anton M, Alen F, Gomez de Heras R, Serrano A, Pavón FJ, Leza JC, García-Bueno B, Rodríguez de Fonseca F and Orio L: Oleoylethanolamide prevents neuroimmune HMGB1/TLR4/NF- $\mathrm{BB}$ danger signaling in rat frontal cortex and depressive-like behavior induced by ethanol binge administration. Addict Biol 22: 724-741, 2017.

32. Lan KC, Chao SC, Wu HY, Chiang CL, Wang CC, Liu SH and Weng TI: Salidroside ameliorates sepsis-induced acute lung injury and mortality via downregulating NF- $\kappa \mathrm{B}$ and HMGB1 pathways through the upregulation of SIRT1. Sci Rep 7: 12026, 2017.

33. Huang W, Tang Y and Li L: HMGB1, a potent proinflammatory cytokine in sepsis. Cytokine 51: 119-126, 2010.

34. Li YB, Xu P, Xu K, Cai YS, Sun MY, Yang L, Sun J and Lu SM: Methotrexate affects HMGB1 expression in rheumatoid arthritis, and the downregulation of HMGB1 prevents rheumatoid arthritis progression. Mol Cell Biochem 420: 161-170, 2016.

35. Abe A, Kuwata T, Yamauchi C, Higuchi Y and Ochiai A: High mobility group box1 (HMGB1) released from cancer cells induces the expression of pro-inflammatory cytokines in peritoneal fibroblasts. Pathol Int 64: 267-275, 2014.

36. Xu GF, Guo M, Tian ZQ, Wu GZ, Zou XP and Zhang WJ: Increased of serum high-mobility group box chromosomal protein 1 correlated with intestinal mucosal barrier injury in patients with severe acute pancreatitis. World J Emerg Surg 9: 61, 2014.

37. Weng H, Deng Y, Xie Y, Liu H and Gong F: Expression and significance of HMGB1, TLR4 and NF-kappaB p65 in human epidermal tumors. BMC Cancer 13: 311, 2013.

38. Gnanasekar M, Kalyanasundaram R, Zheng G, Chen A, Bosland MC and Kajdacsy-Balla A: HMGB1: A promising therapeutic target for prostate cancer. Prostate Cancer 2013: 157103, 2013.

39. Li W, Wu K, Zhao E, Shi L, Li R, Zhang P, Yin Y, Shuai X, Wang $\mathrm{G}$ and Tao K: HMGB1 recruits myeloid derived suppressor cells to promote peritoneal dissemination of colon cancer after resection. Biochem Biophys Res Commun 436: 156-161, 2013.

40. Widdison AL: Sodium fusidate and the cytokine response in an experimental model of acute pancreatitis. Br J Surg 86: 715, 1999.

41. Nicoletti F,Zaccone P, Di Marco R, Magro G, Grasso S, Morrone S, Santoni A, Tempera G, Meroni PL and Bendtzen K: Effects of sodium fusidate in animal models of insulin-dependent diabetes mellitus and septic shock. Immunology 85: 645-650, 1995.

This work is licensed under a Creative Commons Attribution-NonCommercial-NoDerivatives 4.0 International (CC BY-NC-ND 4.0) License. 